\title{
Association between masturbation and functional outcome in the postoperative course after nerve-sparing radical prostatectomy
}

\author{
Valentin H. Meissner ${ }^{1}$, Sonja Dumler ${ }^{1}$, Martina Kron ${ }^{2}$, Stefan Schiele ${ }^{1}$, Veronika E. Goethe ${ }^{1}$, \\ Andreas Bannowsky ${ }^{3}$, Jürgen E. Gschwend ${ }^{1}$, Kathleen Herkommer ${ }^{1}$
}

${ }^{1}$ Technical University of Munich, School of Medicine, Klinikum rechts der Isar, Department of Urology, Munich, Germany; ${ }^{2}$ Institute of Epidemiology and Medical Biometry, University of Ulm, Ulm, Germany; ${ }^{3}$ Department of Urology, Imland Klinik GmbH, Rendsburg, Germany

Contributions: (I) Conception and design: K Herkommer, S Dumler; (II) Administrative support: All authors; (III) Provision of study materials: K Herkommer, JE Gschwend; (IV) Collection and assembly of data: VH Meissner, K Herkommer, S Dumler; (V) Data analysis and interpretation: VH Meissner, K Herkommer, M Kron, S Schiele, VE Goethe, A Bannowsky, JE Gschwend; (VI) Manuscript writing: All authors; (VII) Final approval of manuscript: All authors.

Correspondence to: Kathleen Herkommer, MD, MBA. Technical University of Munich, School of Medicine, Klinikum rechts der Isar, Department of Urology, Ismaninger Straße 22, 81675 Munich, Germany. Email: kathleen.herkommer@tum.de.

\begin{abstract}
Background: Penile rehabilitation after nerve-sparing radical prostatectomy (nsRP) improves the functional outcome, i.e., erectile function and urinary continence. Masturbation as a concept of penile rehabilitation has been practically not investigated. The aim of this observational and explorative study was to evaluate the association between masturbation and the recovery of the functional outcome in patients after nsRP.

Methods: Patients after nsRP (11/2013-3/2016) with preoperative International Erectile Function ScoreErectile Function (IIEF-EF) of $\geq 22$ and/or Erection Hardness Score (EHS) of $\geq 3$ without neo- or adjuvant therapy were included in this analysis. Patients were classified according to their masturbation behavior (yes: m; no: nm). Chi-square tests were used to test for association between masturbation and functional outcome. The main outcome measures were rates of erectile function, morning erections, and urinary continence 6 , 12, 24, and 36 months after nsRP.

Results: A total of 250 preoperatively potent patients with median age of 63.8 years $\left(1^{\text {st }}, 3^{\text {rd }}\right.$ quartile: 59.1 , 69.6) at nsRP were included. After 24 months, m-patients had a numerically higher rate of moderate to good erectile function compared to nm-patients $(47.5 \%$ vs. $37.5 \% ; \mathrm{P}=0.193)$ and had morning erections more often than nm-patients $(54.6 \%$ vs. $34.9 \% ; \mathrm{P}=0.011)$. Urinary continence rate 12 months after nsRP was higher compared to nm-patients (12 months: $83.1 \%$ vs. $70.2 \%$; $\mathrm{P}=0.042$ ).

Conclusions: Masturbation might be a promising approach of both erectile function and urinary continence recovery, and patients could be encouraged to masturbate after nsRP. However, due to the study design, causality cannot be concluded. Thus, masturbation as a possible concept of penile rehabilitation warrants further investigation.
\end{abstract}

Keywords: Erectile function; functional outcome; masturbation; radical prostatectomy (RP); urinary continence

Submitted Oct 29, 2019. Accepted for publication Feb 14, 2020.

doi: $10.21037 /$ tau.2020.03.19

View this article at: http://dx.doi.org/10.21037/tau.2020.03.19

\section{Introduction}

Radical prostatectomy (RP) remains the most commonly used first-line treatment option for patients with clinically localized prostate cancer and a life expectancy of at least
10 years (1). Since RP provides excellent long-term results in terms of cancer-specific and overall survival, an increased focus should lie on the most common adverse effects which negatively affect patients' quality of life: erectile dysfunction and urinary incontinence $(2,3)$. Rates of functional outcome 
(erectile function and urinary continence) after RP vary widely depending on multiple factors including study design, patient age, preoperative erectile status, definition of functional outcome, and comorbidities $(4,5)$.

Recovery of erectile function after RP is especially of increasing importance due to a shift towards earlier stage and younger age at diagnosis $(6,7)$. Therefore, surgeons use nerve-sparing operation techniques for neurovascular bundle preservation which is the major predictor of erectile function recovery $(8,9)$. Montorsi $\mathrm{et} \mathrm{al}$. first introduced the idea of penile rehabilitation with intracavernosal injections (ICIs) of alprostadil in 1997 (10). Several clinical studies about penile rehabilitation followed, mainly focusing on common erectile aids e.g., oral phosphodiesterase type 5 inhibitors (PDE5-I), ICI therapy, intraurethral alprostadil [Medicated Urethral System for Erection (MUSE®)] therapy, and vacuum erection devices (VED) $(11,12)$. For men who fail these more conservative strategies, inflatable penile prosthesis implantation might be a definitive ED treatment (13) with an excellent cost-effectiveness (14). The basic idea of the aforementioned more conservative strategies of penile rehabilitation is prevention of hypoxia in the penile tissue related to cavernous nerve neuropraxia after RP which leads to fibrosis and atrophy of the corporal smooth muscle cells (15). Iacono et al. showed that 2 months after RP, elastic fibers and smooth muscle cells were already significantly decreased whereas collagen content was significantly increased (16). These tissue alterations cause subsequent veno-occlusive dysfunction and consequently reduce the chance of long-term recovery of erectile function. Capogrosso et al. showed recently that, despite the advancements in surgical and post-RP care, erectile function outcomes after RP have not improved over the last 10 years. The authors claimed further strategies to improve recovery of erectile function (17).

The idea of masturbation as a possible penile rehabilitation strategy was already mentioned by Walker et al. 2015 (18), however, it has only been investigated by one small Japanese study including 8 patients which found better results of erectile response in patients who used a masturbation device compared to non-users who only masturbated (19).

The other relevant adverse effect after RP is urinary incontinence. Especially climacturia is linked to low sexual satisfaction and moreover to low quality of life (20). Besides the grade of nerve sparing, the most relevant preoperative risk factors for urinary incontinence are age, body mass index, comorbidity index and lower urinary tract symptoms
$(5,21)$. Postoperative erectile dysfunction 12 months after $\mathrm{RP}$ has also been shown to be a risk factor for urinary incontinence. Thus, Tsikis et al. suggested a possible common pathway for these two adverse effects (22).

Nevertheless, there is a notable research gap concerning the role of masturbation in the postoperative course after nerve-sparing radical prostatectomy (nsRP). The objective of this observational and explorative study was therefore to evaluate a possible association between masturbation and a better functional outcome, i.e., recovery of erectile function and urinary continence, in patients 6 to 36 months after nsRP.

\section{Methods}

\section{Study procedure}

Data of patients who underwent nsRP between 11/2013 and 03/2016 at our institution was analyzed. All patients with neo- or adjuvant therapy and patients with preoperative erectile dysfunction [defined as IIEF-EF <22 (23) and EHS $<3$ (24)] were excluded. All data [preoperative (0), 6, 12, 24 , and 36 months after nsRP] was collected prospectively. Written informed consent was obtained from all patients. The study was approved by the ethical review committee of the Technical University of Munich.

\section{Measures}

Clinical data at baseline [preoperative (indicated as 0 months after nsRP)] was collected including comorbidities [Charlson comorbidity index (CCI) (25)], prostatespecific antigen (PSA) level, age at surgery, use of erectile aids (PDE5-I, ICI, MUSE®, VED), urinary continence, erectile function (IIEF-EF/EHS and frequency of morning erections), and masturbation behavior. Masturbation behavior was assessed by asking surveyed patients, "How often did you practice masturbation in the past four weeks (without the presence of others), that is stimulating your genitals for sexual pleasure (masturbation)?" (no; yes, a few times per month to once per week; 2-3 times per week; $\geq 4$ times per week). This question was taken from Lindau et al. (26). Due to the low number of patients in certain subgroups, i.e., $\geq 4$ times per week, masturbation was dichotomized, and patients were classified into two groups: men who masturbated (m-patients) and men who did not masturbate (nm-patients) within the last four weeks. The quality of nsRP was assessed via the nerve sparing score 
(NSS). In this context, both neurovascular bundles were assigned a grade ranging from 1 (complete preservation) to 4 (complete resection) by the surgeon, respectively. The total score is calculated by summing up the two bundles (27). For this analysis, all patients with NSS $>6$ were excluded.

Follow-up data was collected by mail 6, 12, 24 and 36 months after surgery using standardized, selfadministrated questionnaires. To determine recovery of erectile function, two validated, standardized questionnaires (IIEF-EF and EHS) were analyzed. Similar to previous studies (28-30), we used an IIEF-EF cut-off of $\geq 17$ to define recovery of erectile function. Rigidity of the penis was analyzed using the EHS and erectile function was defined as EHS $\geq 3$. Frequency of morning erections was assessed by the question "How often did you have morning erections (including incomplete erections) in the past 4 weeks?". Recovery of erectile function was defined as the occurrence of morning erections at least occasionally (occasionally; often/mostly; almost ever/ever). Urinary continence was evaluated by the number of used pads, their condition after $24 \mathrm{~h}$ (dry; moist; wet) and defined as the use of a maximum of one dry safety pad per $24 \mathrm{~h}$. Besides parameters of the functional outcome, we additionally assessed use of erectile aids (PDE5-I, ICI, MUSE®, VED) and masturbation behavior during follow-up.

\section{Statistical analysis}

Sociodemographic and clinical characteristics of the study population were analyzed with descriptive statistics calculating counts and percentages for categorical variables. Chi-square tests were used to test for association between masturbation and functional outcome. All analyses were performed using SAS 9.3 (SAS Institute, Cary, NC, USA).

\section{Results}

Table 1 depicts the sociodemographic, clinical and histopathological characteristics of the study population. Between 11/2013 and 03/2016, 250 patients with clinically localized prostate cancer who underwent nsRP in our institution were included in the analysis. Median age at nsRP was 64.0 years $\left(1^{\text {st }}, 3^{\text {rd }}\right.$ quartile: $58.8,69.6$ years $)$ and median PSA level at diagnosis was $6.6 \mathrm{ng} / \mathrm{mL}\left(1^{\text {st }}, 3^{\text {rd }}\right.$ quartile: $5.2,10.0)$. Most patients had a CCI $\leq 1(91.9 \%)$ and a nerve sparing score ranging from $2-4$ (93.2\%), respectively.

Preoperatively, all patients had a good erectile function
(62.8\% IIEF-EF $\geq 22 ; 86.0 \%$ EHS $\geq 3$ ). $23.2 \%$ of the patients with an EHS $\geq 3$ had an IIEF-EF score of $<22$ (Table 1). Most patients reported regular morning erections $(79.8 \%)$ and were sexually active (86.9\%) (Table 2$)$.

At 6, 12, 24, and 36 months after surgery, approximately two thirds $(64.2-71.4 \%)$ of patients reported that they had masturbated within the last 4 weeks. Overall, urinary continence rate was $78.3 \%$ after 12 months and increased to $81.9 \%$ and $82.7 \%$ after 24 and 36 months, respectively. After 24 months, rates of moderate to good erectile function (IIEF-EF $\geq 17$ and/or EHS $\geq 3$ ) and regular morning erections were $43.6 \%$ and $48.1 \%$, respectively. Use of PDE5-I and other erectile aids did not differ between m-patients and nm-patients within the first 12 months. 24 and 36 months after surgery, use of PDE5-I was about twice as high in m-patients compared to nm-patients (24 months: $30.0 \%$ vs. $14.1 \%$ and 36 months: $29.9 \%$ vs. $17.9 \%$ ) (Table 2).

Twenty-four and 36 months after surgery, rates of moderate to good erectile function were numerically higher in m-patients compared to nm-patients (47.5\% vs. $37.5 \%, \mathrm{P}=0.193$ and $47.7 \%$ vs. $35.7 \%, \mathrm{P}=0.286$ ) (Figure 1 ). Rate of morning erections at the same time points of the follow-up showed similar results (24 months: $54.6 \%$ vs. $34.9 \%, \mathrm{P}=0.011$ and 36 months: $52.2 \%$ vs. $35.7 \%, \mathrm{P}=0.141$ ) (Figure 2). 12 months after surgery, the rate of urinary continence was higher in $\mathrm{m}$-patients compared to $\mathrm{nm}$ patients $(83.1 \%$ vs. $70.2 \%, \mathrm{P}=0.042)$ (Figure 3).

\section{Discussion}

Although nsRP is used to preserve the neurovascular bundle, erectile dysfunction and urinary incontinence remain the most bothersome adverse effects $(4,5)$. There are various therapeutic approaches such as use of PDE5-I, ICI, MUSE®, VED, and pelvic floor training to improve patients' functional outcome. To our knowledge, this is the first study investigating an association between masturbation and the functional outcome of patients after nsRP. We found better rates of erectile function, morning erections, and urinary continence in patients who masturbated in the postoperative course after nsRP than in patients without masturbation.

While previous studies assessed erectile function after nsRP using the IIEF-EF, we used both the IIEF$\mathrm{EF}$ and the EHS. Since the IIEF-EF is not applicable to patients without sexual intercourse, by additionally using the EHS we could therefore include almost a third more preoperatively potent men in our analysis. Overall, the rates 
Table 1 Sociodemographic, clinical, sexual, and histopathological characteristics of the study population $(\mathrm{n}=250)$

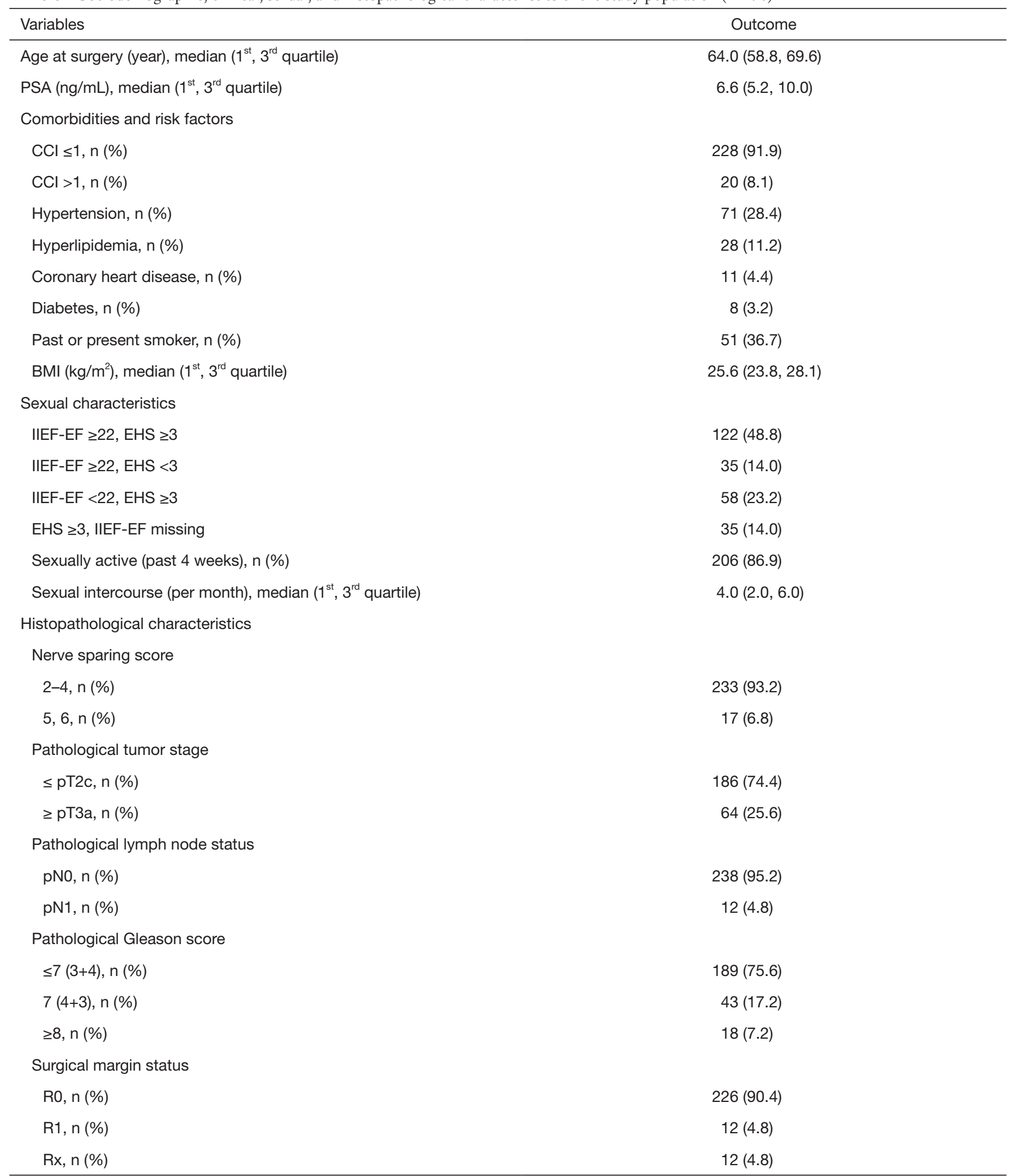

$\mathrm{CCl}$, Charlson comorbidity index; BMI, body mass index; IIEF-EF, International Index of Erectile Function-Erectile Function; EHS, erection hardness score. 
Table 2 Pre- and postoperative variables of the study population $(\mathrm{n}=250)$

\begin{tabular}{|c|c|c|c|c|c|c|c|c|c|c|}
\hline \multirow{2}{*}{ Variables } & \multicolumn{10}{|c|}{ Months after surgery } \\
\hline & $\mathrm{n}$ & (\%) & $\mathrm{n}$ & (\%) & $\mathrm{n}$ & (\%) & $\mathrm{n}$ & $(\%)$ & $\mathrm{n}$ & $(\%)$ \\
\hline \multicolumn{11}{|l|}{ Masturbation } \\
\hline Yes & 154 & $(64.2)$ & 140 & $(65.7)$ & 142 & $(71.4)$ & 120 & $(65.2)$ & 67 & $(70.5)$ \\
\hline 2-3 times/week & 26 & $(10.8)$ & 30 & $(14.1)$ & 26 & $(13.1)$ & 24 & $(13.0)$ & 12 & $(12.6)$ \\
\hline$\geq 4$ times/week & 10 & $(4.2)$ & 6 & $(2.8)$ & 8 & $(4.0)$ & 8 & $(4.4)$ & 2 & (2.1) \\
\hline No & 86 & $(35.8)$ & 73 & $(34.3)$ & 57 & $(28.6)$ & 64 & $(34.8)$ & 28 & $(29.5)$ \\
\hline \multicolumn{11}{|l|}{ PDE5-I } \\
\hline \multicolumn{11}{|l|}{ Intracavernosal injections } \\
\hline m-patients & - & - & 4 & $(2.9)$ & 7 & $(4.9)$ & 2 & $(1.7)$ & 3 & $(4.5)$ \\
\hline nm-patients & - & - & 1 & $(1.4)$ & 2 & $(3.5)$ & 2 & $(3.1)$ & 1 & $(3.6)$ \\
\hline \multicolumn{11}{|l|}{ MUSE $^{\circledR}$} \\
\hline m-patients & - & - & 0 & $(0.0)$ & 1 & $(0.7)$ & 1 & $(0.8)$ & 0 & $(0.0)$ \\
\hline nm-patients & - & - & 0 & $(0.0)$ & 1 & $(1.8)$ & 1 & $(1.6)$ & 0 & $(0.0)$ \\
\hline \multicolumn{11}{|l|}{ Vacuum erection devices } \\
\hline m-patients & - & - & 8 & $(5.7)$ & 7 & $(4.9)$ & 2 & $(1.7)$ & 5 & (7.5) \\
\hline \multicolumn{11}{|l|}{ Morning erections } \\
\hline Yes (at least occasionally) & 197 & $(79.8)$ & 62 & $(29.0)$ & 80 & $(39.8)$ & 89 & $(48.1)$ & 48 & $(48.0)$ \\
\hline No & 50 & $(20.2)$ & 152 & $(71.0)$ & 121 & $(60.2)$ & 96 & $(51.9)$ & 52 & $(52.0)$ \\
\hline \multicolumn{11}{|l|}{ Urinary continence } \\
\hline Yes ( $\leq 1$ dry safety pad/24 h) & 250 & $(100.0)$ & 160 & $(74.8)$ & 162 & $(78.3)$ & 154 & $(81.9)$ & 86 & $(82.7)$ \\
\hline No ( $\geq 1$ moist safety pad/24 h) & 0 & $(0.0)$ & 54 & $(25.2)$ & 45 & $(21.7)$ & 34 & $(18.1)$ & 18 & $(17.3)$ \\
\hline
\end{tabular}

PDE5-I, phosphodiesterase type 5 inhibitors; m, masturbating; nm, non-masturbating; MUSE ${ }^{\circledR}$, Medicated Urethral System for Erection; IIEF-EF, International Index of Erectile Function-Erectile Function; EHS, erection hardness score.

of erectile function among our patients were $38.1 \%$ and $43.6 \%$ after 12 and 24 months, respectively. These rates appear to be low compared to potency rates in a systematic review and meta-analysis by Ficarra $e t$ al. ranging between
$47 \%$ and $94 \% 24$ months after nsRP (4). However, it should be noted that most of these studies included only highly-selected young patients with low-risk prostate cancer whereas the median age of our patients was 64.0 years 


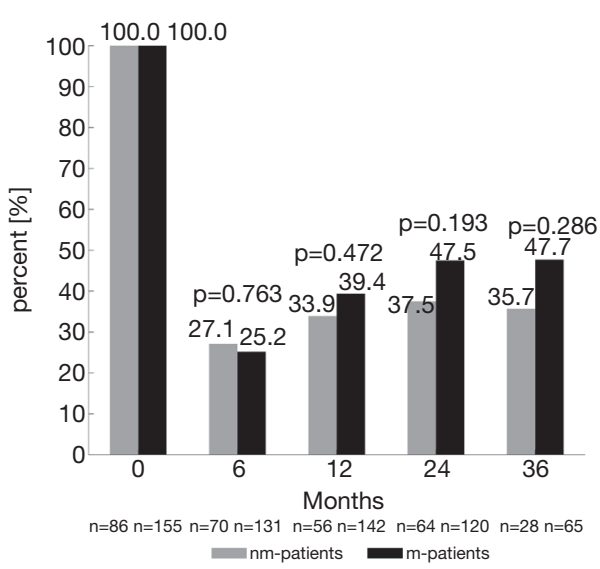

Figure 1 Postoperative rates of moderate to good erectile function (IIEF $\geq 17$ and/or EHS $\geq 3$ ) in nm- and m-patients.

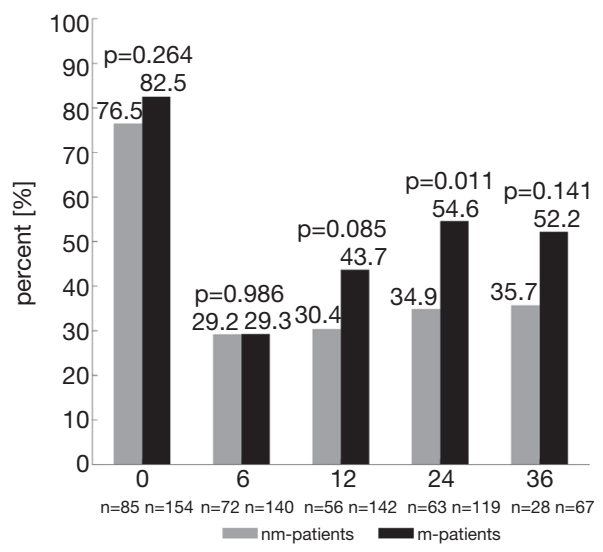

Figure 2 Postoperative rates of regular morning erections in nmand m-patients.

and almost a quarter were either not organ-confined ( $\geq$ pT3a) or had a pathological Gleason score $\geq 7(3+4)$, thus representing a more heterogeneous sample. Compared to other large prospective studies with similarly heterogeneous samples concerning age, comorbidities, and tumor stage, our rates of erectile function were similar or even slightly higher $(17,31)$.

Rates of morning erections were assessed as an additional aspect of erectile function and can be an indicator for sleep-related erections. The impact of mental factors on erectile function is lower during sleep than during sexual activity (32), which might explain the slightly higher rates of morning erections compared to rates of erectile function using the IIEF-EF/EHS among our patients (48.1\% vs. $43.6 \%$ after 24 months).

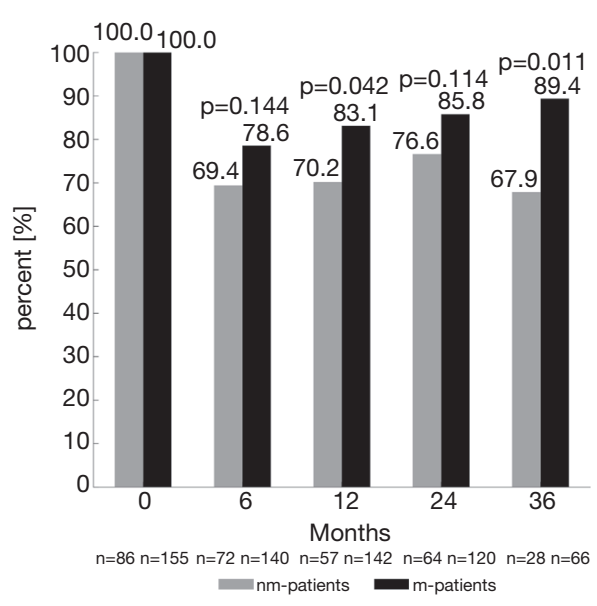

Figure 3 Postoperative rates of urinary continence ( $\leq 1$ dry safety $\mathrm{pad} / 24 \mathrm{~h}$ ) in $\mathrm{nm}$ - and m-patients.

Compared to established methods of penile rehabilitation after nsRP such as PDE5-I, ICI/MUSE® therapy or VED, there are no studies about masturbation as a concept of penile rehabilitation. The rationale of penile rehabilitation is protection of penile tissue against reduced blood flow and hypoxia and thus avoiding structural changes such as smooth muscle apoptosis and local fibrosis which lead to erectile dysfunction $(11,33)$. The authors of a review about sexual recovery after prostate cancer treatment hypothesized that masturbation might have a similar effect on penile tissue and could lead to better recovery of erectile function (18). Indeed, our results showed that the rate of erectile function (IIEF-EF/EHS) 24 months after nsRP was numerically higher in m-patients compared to nm-patients $(47.5 \%$ vs. $37.5 \%)$. This difference of $10.0 \%$ between the two groups is clinically relevant, but not statistically significant due to the somewhat limited sample size of 184 patients at 24 months after nsRP. Moreover, the rate of morning erections showed similar results, with an even larger difference in rates between $\mathrm{m}$-patients and nm-patients after 24 months (54.6\% vs. $34.9 \%$ ). These results might be explained by similar molecular mechanisms that are known to improve penile rehabilitation when using VED. In a rat model of bilateral cavernous nerve crush, VED therapy preserved erectile function through an increase of blood flow and thus antihypoxic and antifibrotic effects (34). In humans, penile oxygen saturation in the flaccid penis is about $49 \%$ and increases to $67 \%$ after using VED $(35,36)$. However, this is not as high as it becomes after ICIs with prostaglandin (78.5\%) (36). The corporal blood after VED use consists of both arterial and venous blood, hence the oxygen saturation 
is lower (37), whereas only the arterial blood flow increases through masturbation, which leads to higher penile oxygen saturation. The presence of fibrogenic cytokines e.g., TGF- $\beta 1$, ET-1, NGF, and HIF-1 $\alpha$ have confirmed hypoxia as possible pathophysiological cause of erectile dysfunction $(33,38-40)$. Rahardjo et al. recently reported that TGF- $\beta 1$ levels already decrease significantly at tumescence and even more at rigidity (40). Accordingly, masturbation might have a protective effect on penile tissue, and this might explain why long-term outcomes of erectile function were better in $\mathrm{m}$-patients than in nm-patients.

To date, due to conflicting results, current evidence does not support that penile rehabilitation with PDE5-I improves recovery of spontaneous erectile function (12). However, in a study investigating the combination of PDE5-I and VED, rates of IIEF-5 were significantly higher after 12 months in the combination group compared to the PDE5-I group (92\% vs. 57\%) (41). Combination of masturbation and PDE5-I could show a similar effect since they enhance the blood flow during sexual stimulation and arousal and could lead to better oxygenation. Finally, if masturbation is the reason for the better erectile function or if better erectile function leads to more masturbation remains unclear. Nonetheless, masturbation, which causes neither costs nor adverse effects might be another interesting approach for penile rehabilitation and warrants further investigation.

In light of favorable oncologic outcomes of prostate cancer patients after nsRP, quality of life is highly important, in particular the recovery of urinary continence. Prevalence of urinary continence after nsRP depends on the definition. With the use of a maximum of one dry safety pad per $24 \mathrm{~h}$ we used a very strict definition of urinary continence. Twelve months after nsRP, continence was $78.3 \%$ among our patients. This stands in line with other recently published studies that reported urinary continence rates between $74 \%$ and $77 \% 12$ months after nsRP $(42,43)$. Contrary to the findings of Penson et al., who indicated stable rates of urinary continence 12-60 months after nsRP (44), the rate of urinary continence among our patients improved from $78.3 \%$ to $81.9 \% 24$ months after nsRP. Likewise, Lee et al. reported a proportion of patients achieving urinary continence at 24,36 , and 48 months of $30 \%, 49 \%$, and $59 \%$, in patients incontinent at 12 months after nsRP (45).

We found that $m$-patients had better rates of urinary continence 12 months after nsRP than nm-patients $(83.1 \%$ vs. $70.2 \%)$. Preservation of the neurovascular bundle through nerve-sparing techniques is associated highly with urinary continence $(46,47)$. This supports the idea that cavernous nerves play an important role in recovery of urinary continence. Therefore, masturbation could enhance urinary continence through increasing pelvic blood flow and oxygen supply, with a positive effect on sphincter function. Based on a similar assumption, the authors of several studies showing an improvement of urinary continence with PDE5-I tried to justify their results (48-50). Gandaglia et al. reported a higher urinary continence rate in patients taking PDE5-I compared to untreated patients (86.7\% vs. $67.1 \%)$ (49). This again underlines the important role of sphincteric and pelvic floor blood supply and the accompanying higher oxygen saturation (50).

The present study is the first attempt to investigate the association between masturbation and functional outcome in a sample of patients treated with nsRP. One strength of our study is the heterogeneous sample of patients with various tumor stages and histopathological characteristics. Another strength is the prospective data collection; however, we could not infer causality, but only associations. This is due to the nature of the intervention since it is hardly possible to initiate a randomized controlled trial prohibiting the control group to masturbate, whereas the intervention group is encouraged to masturbate. Therefore, if masturbation is the reason for the better functional outcome or if a better functional outcome leads to more masturbation remains unclear. Moreover, we could not control for comorbidities and risk factors in a multiple regression model due to missing data of certain variables. Furthermore, m-patients and nm-patients could have changed their groups between the different time points after nsRP which might lead to inconsistent groups across time points and thus rates should be compared over time with caution, since they are not directly comparable. Therefore, we analyzed each time point separately and conducted a cross-sectional analysis at each different time point (6, 12, 24, and 36 months). Based on our findings, further studies could provide interesting data when using a strict longitudinal study design. Excluding subjects with a missing value for masturbation status at any time point $22 \%$ of the patients changed between the $\mathrm{m}$-group and $\mathrm{nm}$-group, which limits the interpretation of our results. Another limitation is that data of the main outcome measures are self-reported and at risk for exaggeration and misrepresentation. In addition, although we asked patients about their masturbation frequency, we could not examine whether there are different erectile function outcomes among these subgroups, due to the low number of patients 
in each category. Finally, we did not assess whether patients masturbated with an erect or soft penis.

In conclusion, this is the first study that investigated an association between masturbation and both better erectile function and urinary continence of patients treated with nsRP. If masturbation is the reason for the better functional outcome or if a better functional outcome leads to more masturbation remains unclear and needs to be confirmed in future studies consisting of larger samples, since randomized controlled trials are difficult to accomplish. Nonetheless, masturbation, which neither causes any costs nor adverse effects might be a promising approach for erectile function and urinary continence recovery, and patients could be encouraged to masturbate after nsRP.

\section{Acknowledgments}

Funding: This work was supported by the German Research Foundation (DFG) and the Technical University of Munich within the funding program Open Access Publishing.

\section{Footnote}

Conflicts of Interest: All authors have completed the ICMJE uniform disclosure form (available at http://dx.doi. org/10.21037/tau.2020.03.19). The authors have no conflicts of interest to declare.

Ethical Statement: The authors are accountable for all aspects of the work in ensuring that questions related to the accuracy or integrity of any part of the work are appropriately investigated and resolved. The study was approved by the ethical review committee of the Technical University of Munich. Written informed consent was obtained from all patients.

Open Access Statement: This is an Open Access article distributed in accordance with the Creative Commons Attribution-NonCommercial-NoDerivs 4.0 International License (CC BY-NC-ND 4.0), which permits the noncommercial replication and distribution of the article with the strict proviso that no changes or edits are made and the original work is properly cited (including links to both the formal publication through the relevant DOI and the license). See: https://creativecommons.org/licenses/by-nc-nd/4.0/.

\section{References}

1. Bill-Axelson A, Holmberg L, Garmo H, et al. Radical prostatectomy or watchful waiting in early prostate cancer. New Engl J Med 2014;370:932-42.

2. Johansson E, Steineck G, Holmberg L, et al. Longterm quality-of-life outcomes after radical prostatectomy or watchful waiting: the Scandinavian Prostate Cancer Group-4 randomised trial. Lancet Oncol 2011;12:891-9.

3. Buckley BS, Lapitan MC, Glazener CM. The effect of urinary incontinence on health utility and healthrelated quality of life in men following prostate surgery. Neurourol Urodyn 2012;31:465-9.

4. Ficarra V, Novara G, Ahlering TE, et al. Systematic review and meta-analysis of studies reporting potency rates after robot-assisted radical prostatectomy. Eur Urol 2012;62:418-30.

5. Ficarra V, Novara G, Rosen RC, et al. Systematic review and meta-analysis of studies reporting urinary continence recovery after robot-assisted radical prostatectomy. Eur Urol 2012;62:405-17.

6. Welch HG, Albertsen PC. Prostate cancer diagnosis and treatment after the introduction of prostate-specific antigen screening: 1986-2005. J Natl Cancer Inst 2009;101:1325-9.

7. Kelly SP, Rosenberg PS, Anderson WF, et al. Trends in the Incidence of Fatal Prostate Cancer in the United States by Race. Eur Urol 2017;71:195-201.

8. Marien T, Sankin A, Lepor H. Factors predicting preservation of erectile function in men undergoing open radical retropubic prostatectomy. J Urol 2009;181:1817-22.

9. Pavlovich CP, Rocco B, Druskin SC, et al. Urinary continence recovery after radical prostatectomy anatomical/reconstructive and nerve-sparing techniques to improve outcomes. BJU Int 2017;120:185-96.

10. Montorsi F, Guazzoni G, Strambi LF, et al. Recovery of spontaneous erectile function after nerve-sparing radical retropubic prostatectomy with and without early intracavernous injections of alprostadil: results of a prospective, randomized trial. J Urol 1997;158:1408-10.

11. Gandaglia G, Suardi N, Cucchiara V, et al. Penile rehabilitation after radical prostatectomy: does it work? Transl Androl Urol 2015;4:110-23.

12. Liu C, Lopez DS, Chen M, et al. Penile Rehabilitation Therapy Following Radical Prostatectomy: A MetaAnalysis. J Sex Med 2017;14:1496-503.

13. Dadhich P, Hockenberry M, Kirby EW, et al. Penile prosthesis in the management of erectile dysfunction following cancer therapy. Transl Androl Urol 2017;6:S883-9. 
14. Moses RA, Anderson RE, Kim J, et al. Erectile dysfunction management after failed phosphodiesterase-5-inhibitor trial: a cost-effectiveness analysis. Transl Androl Urol 2019;8:387-94.

15. Moreland RB. Is there a role of hypoxemia in penile fibrosis: a viewpoint presented to the Society for the Study of Impotence. Int J Impot Res 1998;10:113-20.

16. Iacono F, Giannella R, Somma P, et al. Histological alterations in cavernous tissue after radical prostatectomy. J Urol 2005;173:1673-6.

17. Capogrosso P, Vertosick EA, Benfante NE, et al. Are We Improving Erectile Function Recovery After Radical Prostatectomy? Analysis of Patients Treated over the Last Decade. Eur Urol 2019;75:221-8.

18. Walker LM, Wassersug RJ, Robinson JW. Psychosocial perspectives on sexual recovery after prostate cancer treatment. Nat Rev Urol 2015;12:167-76.

19. Sato $Y$, Tanda H, Nakajima H, et al. Masturbation device (EGG) as a new penile rehabilitation tool: a pilot study. Hinyokika Kiyo 2013;59:271-5.

20. Mendez MH, Sexton SJ, Lentz AC. Contemporary Review of Male and Female Climacturia and Urinary Leakage During Sexual Activities. Sex Med Rev 2018;6:16-28.

21. Steineck G, Bjartell A, Hugosson J, et al. Degree of preservation of the neurovascular bundles during radical prostatectomy and urinary continence 1 year after surgery. Eur Urol 2015;67:559-68.

22. Tsikis ST, Nottingham CU, Faris SF. The Relationship Between Incontinence and Erectile Dysfunction After Robotic Prostatectomy: Are They Mutually Exclusive? J Sex Med 2017;14:1241-47.

23. Cappelleri JC, Rosen RC, Smith MD, et al. Diagnostic evaluation of the erectile function domain of the International Index of Erectile Function. Urology 1999;54:346-51.

24. Mulhall JP, Goldstein I, Bushmakin AG, et al. Validation of the erection hardness score. J Sex Med 2007;4:1626-34.

25. Charlson ME, Pompei P, Ales KL, et al. A new method of classifying prognostic comorbidity in longitudinal studies: development and validation. J Chron Dis 1987;40:373-83.

26. Lindau ST, Schumm LP, Laumann EO, et al. A study of sexuality and health among older adults in the United States. New Engl J Med 2007;357:762-74.

27. Moskovic DJ, Alphs H, Nelson CJ, et al. Subjective characterization of nerve sparing predicts recovery of erectile function after radical prostatectomy: defining the utility of a nerve sparing grading system. J Sex Med 2011;8:255-60.
28. Ficarra V, Novara G, Galfano A, et al. Twelve-month self-reported quality of life after retropubic radical prostatectomy: a prospective study with Rand 36-Item Health Survey (Short Form-36). BJU Int 2006;97:274-8.

29. Garcia FJ, Violette PD, Brock GB, et al. Predictive factors for return of erectile function in robotic radical prostatectomy: case series from a single centre. Int J Impot Res 2015;27:29-32.

30. Giovannone R, Busetto GM, Antonini G, et al. Hyperhomocysteinemia as an Early Predictor of Erectile Dysfunction: International Index of Erectile Function (IIEF) and Penile Doppler Ultrasound Correlation With Plasma Levels of Homocysteine. Medicine 2015;94:e1556.

31. Haglind E, Carlsson S, Stranne J, et al. Urinary Incontinence and Erectile Dysfunction After Robotic Versus Open Radical Prostatectomy: A Prospective, Controlled, Nonrandomised Trial. Eur Urol 2015;68:216-25.

32. van Driel MF. Sleep-related erections throughout the ages. J Sex Med 2014;11:1867-75.

33. Fode M, Ohl DA, Ralph D, et al. Penile rehabilitation after radical prostatectomy: what the evidence really says. BJU Int 2013;112:998-1008.

34. Yuan J, Lin H, Li P, et al. Molecular mechanisms of vacuum therapy in penile rehabilitation: a novel animal study. Eur Urol 2010;58:773-80.

35. Welliver RC Jr, Mechlin C, Goodwin B, et al. A pilot study to determine penile oxygen saturation before and after vacuum therapy in patients with erectile dysfunction after radical prostatectomy. J Sex Med 2014;11:1071-7.

36. Padmanabhan P, McCullough AR. Penile oxygen saturation in the flaccid and erect penis in men with and without erectile dysfunction. J Androl 2007;28:223-8.

37. Qian SQ, Gao L, Wei Q, et al. Vacuum therapy in penile rehabilitation after radical prostatectomy: review of hemodynamic and antihypoxic evidence. Asian J Androl 2016;18:446-51.

38. Kovanecz I, Rambhatla A, Ferrini M, et al. Long-term continuous sildenafil treatment ameliorates corporal venoocclusive dysfunction (CVOD) induced by cavernosal nerve resection in rats. Int J Impot Res 2008;20:202-12.

39. Leungwattanakij S, Bivalacqua TJ, Usta MF, et al. Cavernous neurotomy causes hypoxia and fibrosis in rat corpus cavernosum. J Androl 2003;24:239-45.

40. Rahardjo HE, Uckert S, Bannowsky A, et al. Course of transforming growth factor ss 1 in the systemic and cavernous blood of healthy males through different penile conditions. Andrologia 2019;51:e13150. 
41. Engel JD. Effect on sexual function of a vacuum erection device post-prostatectomy. Can J Urol 2011;18:5721-5.

42. Donovan JL, Hamdy FC, Lane JA, et al. Patient-Reported Outcomes after Monitoring, Surgery, or Radiotherapy for Prostate Cancer. New Engl J Med 2016;375:1425-37.

43. Tienza A, Robles JE, Hevia M, et al. Prevalence analysis of urinary incontinence after radical prostatectomy and influential preoperative factors in a single institution. Aging Male 2018;21:24-30.

44. Penson DF, McLerran D, Feng Z, et al. 5-year urinary and sexual outcomes after radical prostatectomy: results from the prostate cancer outcomes study. J Urol 2005;173:1701-5.

45. Lee JK, Assel M, Thong AE, et al. Unexpected Long-term Improvements in Urinary and Erectile Function in a Large Cohort of Men with Self-reported Outcomes Following Radical Prostatectomy. Eur Urol 2015;68:899-905.

46. Burkhard FC, Kessler TM, Fleischmann A, et al. Nerve sparing open radical retropubic prostatectomy-

Cite this article as: Meissner VH, Dumler S, Kron M, Schiele S, Goethe VE, Bannowsky A, Gschwend JE, Herkommer K. Association between masturbation and functional outcome in the postoperative course after nerve-sparing radical prostatectomy. Transl Androl Urol 2020;9(3):1286-1295. doi:10.21037/tau.2020.03.19 -does it have an impact on urinary continence? J Urol 2006;176:189-95.

47. Kaye DR, Hyndman ME, Segal RL, et al. Urinary outcomes are significantly affected by nerve sparing quality during radical prostatectomy. Urology 2013;82:1348-53.

48. Gacci M, Ierardi A, Rose AD, et al. Vardenafil can improve continence recovery after bilateral nerve sparing prostatectomy: results of a randomized, double blind, placebo-controlled pilot study. J Sex Med 2010;7:234-43.

49. Gandaglia G, Albersen M, Suardi N, et al. Postoperative phosphodiesterase type 5 inhibitor administration increases the rate of urinary continence recovery after bilateral nerve-sparing radical prostatectomy. Int J Urol 2013;20:413-9.

50. Patel HR, Ilo D, Shah N, et al. Effects of tadalafil treatment after bilateral nerve-sparing radical prostatectomy: quality of life, psychosocial outcomes, and treatment satisfaction results from a randomized, placebocontrolled phase IV study. BMC Urol 2015;15:31. 